Soft X-Ray Laser Interferometry of Colliding Laser-Created Plasmas in Semi-Cylindrical Cavities

M. A. Purvis, J. Grava, J. Filevich, M. Marconi, J. Dunn, S. J. Moon, V. N. Shlyaptsev, E. Jankowska, J. J. Rocca

December 12, 2007

Images in Plasma Science, IEEE Transaction in Plasma Science 
This document was prepared as an account of work sponsored by an agency of the United States government. Neither the United States government nor Lawrence Livermore National Security, LLC, nor any of their employees makes any warranty, expressed or implied, or assumes any legal liability or responsibility for the accuracy, completeness, or usefulness of any information, apparatus, product, or process disclosed, or represents that its use would not infringe privately owned rights. Reference herein to any specific commercial product, process, or service by trade name, trademark, manufacturer, or otherwise does not necessarily constitute or imply its endorsement, recommendation, or favoring by the United States government or Lawrence Livermore National Security, LLC. The views and opinions of authors expressed herein do not necessarily state or reflect those of the United States government or Lawrence Livermore National Security, LLC, and shall not be used for advertising or product endorsement purposes. 
IM-3355840

UCRL-

\section{AX-Division \\ Lawrence Livermore National Laboratory}

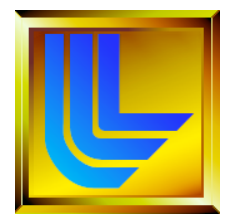

\section{Mike Purvis, Jonathan Grava, Jorge Filevich, Mario C. Marconi, James Dunn, Stephen J. Moon, Vyacheslav N. Shlyaptsev, Elizabeth Jankowska, and Jorge J. Rocca (Fellow IEEE)}

\section{December 10, 2007}

\section{Disclaimer}

This document was prepared as an account of work sponsored by an agency of the United States government. Neither the United States government nor Lawrence Livermore National Security, LLC, nor any of their employees makes any warranty, expressed or implied, or assumes any legal liability or responsibility for the accuracy, completeness, or usefulness of any information, apparatus, product, or process disclosed, or represents that its use would not infringe privately owned rights. Reference herein to any specific commercial product, process, or service by trade name, trademark, manufacturer, or otherwise does not necessarily constitute or imply its endorsement, recommendation, or favoring by the United States government or Lawrence Livermore National Security, LLC. The views and opinions of authors expressed herein do not necessarily state or reflect those of the United States government or Lawrence Livermore National Security, LLC, and shall not be used for advertising or product endorsement purposes. Lawrence Livermore National Laboratory under Contract No. W-7405-Eng-48. 


\title{
Soft X-Ray Laser Interferometry of Colliding Laser-Created Plasmas in Semi-Cylindrical Cavities
}

\author{
Mike Purvis, Jonathan Grava, Jorge Filevich, Mario C. Marconi, James Dunn, Stephen J. Moon, \\ Vyacheslav N. Shlyaptsev, Elizabeth Jankowska, and Jorge J. Rocca (Fellow IEEE)
}

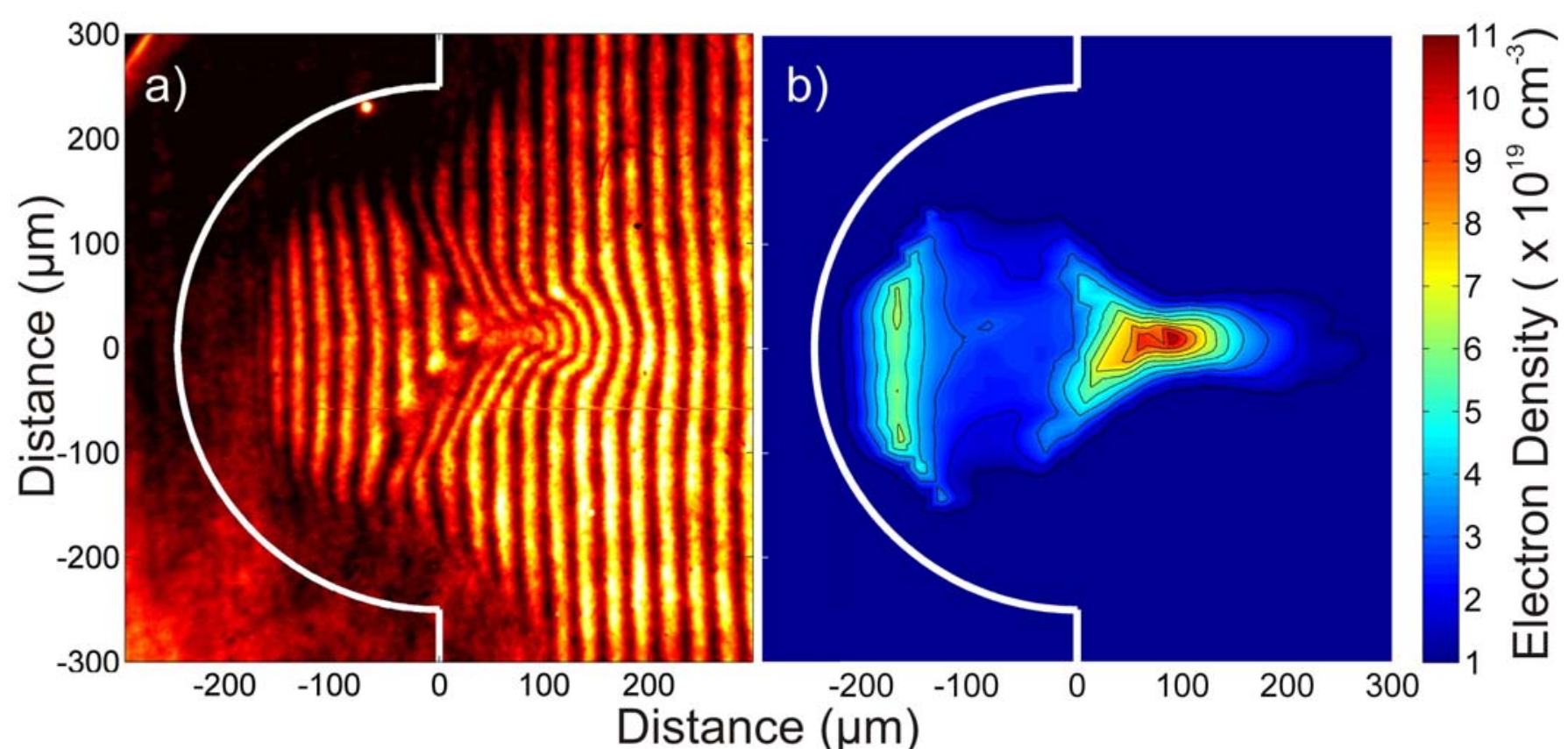

Fig. 1. a) Soft x-ray interferogram of a plasma created by laser irradiation of a $500 \mu \mathrm{m}$ diameter semi-cylindrical Al cavity at an intensity of $1.1 \times 10^{12} \mathrm{Wcm}^{-2}$ with a $120 \mathrm{ps}$ duration laser pulse, and b) the resulting electron density map. The interferogram depicts the plasma $4.4 \mathrm{~ns}$ after the peak of the laser irradiation pulse.

\begin{abstract}
A table-top capillary discharge soft x-ray laser was used to acquire high contrast interferograms that map the evolution of dense aluminum plasmas created by laser irradiation of a $500 \mu \mathrm{m}$ diameter semi-cylindrical cavity with 120 ps optical laser pulses of $\sim 1.1 \times 10^{12} \mathrm{Wcm}^{-}$ ${ }_{2}$ peak intensity. The measured electron density maps, that were compared with simulations, show that the plasma converges on axis, where it collides to form a localized region with density exceeding $1 \times 10^{20} \mathrm{~cm}^{-3}$.
\end{abstract}

Index terms - soft $\mathrm{x}$-ray laser, plasma diagnostics, soft $\mathrm{x}$ ray laser interferometry, colliding plasmas.
Plasmas created by intense laser pulses irradiating solid targets usually expand in directions perpendicular to the target surface, along the strong pressure gradients that are generated by the high temperatures and densities near the wall. For concave target geometries, this direction of expansion can force the laser created plasma to converge into a focal region where it can collide with itself. For example, laser heating of a semi-cylindrical cavity (half-hohlraum) accelerates plasma towards the axis of the cavity where plasma interactions can range from stagnation to extended interpenetration depending on the degree of collisionality of

Manuscript received XXXX.

M. Purvis, J. Grava, J. Filevich, M. C. Marconi and J. J. Rocca are with the NSF ERC for Extreme Ultraviolet Science and Technology and the Department of Electrical and Computer Engineering, Colorado State University, Fort Collins, Colorado 80523, USA

J. Dunn and S. J. Moon are with Lawrence Livermore National Laboratory, Livermore, California 94551, USA

V. N. Shlyaptsev is with the Department of Applied Science, University of California Davis-Livermore, Livermore, California 94551, USA

E. Jankowska is with Wroclaw University of Technology, Wroclaw, Poland

Work was supported by the National Nuclear Security Administration under the Stewardship Science Academic

Alliances program through U.S. Department of Energy Research Grant No. DE-FG52-06NA26152, using facilities from the NSF ERC Center for Extreme Ultraviolet Science and Technology, Grant No.EEC-0310717. Part of this work was performed under the auspices of the U.S. Department of Energy by Lawrence Livermore National Laboratory under Contract DE-AC52-07NA27344. 
the plasma [1]. Detailed electron density maps are very useful to understand the dynamics of these colliding plasmas and for benchmarking plasma simulation codes. However, they are difficult to obtain using optical laser probes due to the presence of strong density gradients that deflect the probe beam. Soft x-ray laser interferometry is a powerful plasma diagnostic tool that has the ability to access very high densities and large scale length plasmas with a reduced refraction and free-free absorption of the probe beam, allowing for the generation of detailed maps of the electron density in high density plasmas [2], [3].

Interferograms were obtained using a Ne-like $\mathrm{Ar}$ $46.9 \mathrm{~nm}$ table-top capillary discharge soft x-ray laser probe beam [4] and an amplitude division soft x-ray interferometer [3]. The probe beam was configured to deliver pulses of $\sim 1$ ns duration and $\sim 0.15 \mathrm{~mJ}$ of energy. The good spatial coherence of this laser assists the generation of interferograms with high fringe visibility. The skewed MachZehnder interferometer uses gold coated diffraction gratings as beam splitters and grazing incidence gold coated mirrors to achieve a high throughput of $\sim 6 \%$ per arm. The dense colliding plasma was created by focusing $600 \mathrm{~mJ}$ pulses of $120 \mathrm{ps}$ duration from a $\lambda=800 \mathrm{~nm}$ Ti:Sapphire laser onto the surface of a semi cylindrical target. The laser beam was smoothed by a vacuum spatial filter and it was shaped into a $310 \mu \mathrm{m}$ wide, $1.5 \mathrm{~mm}$ FWHM long line focus by a pair of cylindrical lenses. The targets consisted of $500 \mu \mathrm{m}$ diameter semi-cylindrical cavities machined onto the edge of a $1 \mathrm{~mm}$ thick aluminum slab. The targets were placed along the zero order arm of the interferometer. The plasmas were imaged with $25 \mathrm{X}$ magnification onto a microchannel-plate/CCD detector using $\mathrm{Sc} / \mathrm{Si}$ multilayer mirrors.

A sequence of interferograms was acquired to map the evolution of the plasma. The interferograms show the early creation of a plasma that expands away from the wall to converge in a small region near the axis of the cavity, where it collides forming a dense plasma focus. The resulting buildup of density at the focus develops as early as $1.5 \mathrm{~ns}$ after the peak of the irradiation pulse, with the electron density progressively increasing to exceed $1 \times 10^{20} \mathrm{~cm}^{-3}$. Figure 1a shows a high contrast soft x-ray interferogram acquired 4.4 ns after the irradiation pulse. The large number of fringe shifts observed slightly to the right of the axis of the cavity describes the high density focal region. Figure $1 \mathrm{~b}$ shows the electron density map constructed from the interferogram.

The single fluid radiation hydrodynamics code HYDRA was used to simulate the 2D symmetric experiment described above and generate time-dependant 2D maps of the electron density and other plasma parameters [5]. The code uses an Arbitrary Lagrangian-Eulerian grid. The simulations show that the peak electron density $\left(1.1 \times 10^{20} \mathrm{~cm}^{-3}\right)$ and electron temperature $(\sim 50 \mathrm{eV})$ at the focus occurs $\sim 2.6 \mathrm{~ns}$ after the irradiation pulse, in good agreement with the experiments. The laser model included the Gaussian-shaped irradiation pulse which shows the creation of a hotter plasma at the bottom of the groove. This plasma expands more rapidly and reaches the axis of the cavity first, where it converges forming the observed high density plasma focus. The later arrival of additional plasma created by plasma radiation-induced ablation of the entire target cavity wall causes the electron density at the focus to remain high until $\sim 7 \mathrm{~ns}$ after the arrival of the irradiation pulse. Subsequently the density is observed to relax as the plasma expands and cools. The ion-ion mean free-path is computed to be nearly two orders of magnitude smaller than the plasma focus size, an indication that the plasma is highly collisional. The good agreement between the experimental results and the simulations with the fluid code HYDRA, which can not model interpenetration, indicates that the plasma is highly collisional and stagnates on axis without significant interpenetration. More information on the dynamics can be found in a recent publication [6].

In conclusion, soft $\mathrm{x}$-ray laser interferometry was used to study dense colliding aluminum plasmas formed by optical irradiation of a semi-cylindrical cavity. The measurements reveal that plasma accumulation near the axis of the cavity creates a highly collisional plasma focus with a density that exceeds $1 \times 10^{20} \mathrm{~cm}^{-3}$. The measurements are in good agreement with hydrodynamic simulations. These results further demonstrate that soft $x$-ray interferometry is a powerful tool for probing dense plasmas.

\section{REFERENCES}

[1.] M. E. Jones, D. Winske, S. R. Goldman, R. A. Kopp, V. G. Rogatchev, S. A. Bel'kov, P. D. Gasparyan, G. V. Dolgoleva, N. V. Zhidkov, N. V. Ivanov, Y. K. Kochubej, G. F. Nasyrov, V. A. Pavlovskii, V. V. Smirnov, and Y. A. Romanov, Phys. Plasmas 3, 1096 (1996).

[2.] L. B. Da Silva, T. W. Barbee, Jr., R. Cauble, P. Celliers, D. Ciarlo, S. Libby, R. A. London, D. Matthews, S. Mrowka, J. C. Moreno, D. Ress, J. E. Trebes, A. S. Wan, and F. Weber, Phys. Rev. Lett. 74, 3991 (1995).

[3.] J. Filevich, K. Kanizay, M. C. Marconi, J. L. A. Chilla, and J. J. Rocca, Optics Letters 25, 356 (2000).

[4.] B. R. Benware, C. D. Macchietto, J. L. A. Chilla, and J. J. Rocca, Phys. Rev. Lett., 81, 5804 (1998).

[5.] M. M. Marinak, S. W. Haan, T. R. Dittrich, R. E. Tipton, and G. B. Zimmerman, Phys. Plasmas 5, 1125 (1998).

[6.] M. Purvis, J. Grava, J. Filevich, M. C. Marconi, J. Dunn, S. J. Moon, V. N. Shlyaptsev, E. Jankowska, and J. J. Rocca, Phys. Rev. E, 76 (2007). 